\title{
Surgical therapy for benign prostatic hyperplasia: Almost three decades of change
}

\author{
J. Curtis Nickel, MD, FRCSC
}

Department of Urology, Queen's University, Kingston, ON, Canada

Cite as: Can Urol Assoc J 2020; 14(8):258. http://dx.doi.org/10.5489/cuaj.6797

See related article on page 252

I n 2001, we published our analysis describing a "decade of change" in the surgical management of benign prostatic hyperplasia $(\mathrm{BPH})$ impacted by the introduction of medical therapy. ${ }^{1}$ We described patients who underwent transurethral resection of the prostate (TURP) for symptomatic BPH in 1988 (before general introduction of medical therapy for BPH) and 1998 (medical therapy as the primary initial therapy for BPH). We believed that medical therapy led to the dramatic decrease in the number of TURPs being performed. The proportion of TURP patients presenting with urinary retention and hydronephrosis increased, but the average age, medical comorbidities, operative parameters, and postoperative complications did not significantly change.

A decade later, in 2011, we published a followup analysis of the impact of medical therapy on TURP, "two decades of change" (1988-2008). ${ }^{2}$ We observed a further decrease in number of TURPs in the second decade (1998-2008). Failure of medical therapy was the indication for TURP in $0 \%, 36 \%$, and $87 \%$ of patients in 1988,1998 , and 2008 , respectively. The second decade of change showed an increased trend for men presenting with retention and/or hydronephrosis, and/or discharge with a Foley catheter.

In this issue of the Canadian Urological Association Journal, LaBossiere and colleagues performed a study of men undergoing surgical treatment for $\mathrm{BPH} /$ benign prostatic obstruction (BPO) between 1994 and 2014 ("20-year ... trends") in Ontario, Canada. ${ }^{3}$ They observed that during this time period, the number of BPO surgeries declined. While overall, TURP still accounted for $91.5 \%$ of the total cases (the proportion declining from a high of $>97 \%$ in 1994), there was an increased use of endoscopic laser prostatectomy after 2002 (reaching almost 23\% in 2014). Among the whole study cohort, they observed a small but statistically significant trend towards higher comorbidity and increasing age among patients undergoing BPO surgery over time.

So what does this large, well-done study tell me that I did not already know from our previous published experience? Unfortunately, not much except that, as expected, more men are undergoing endoscopic laser prostatectomy as time progresses. It remains concerning to me that as the decades march on, we appear to be operating on men with more comorbidities, increased age, and (although not collected in this recent study), perhaps, poorer outcomes. I believe that these studies support the implication that medical therapy may be postponing the inevitable for some men, with delayed operations being associated with higher risk and unfavorable results. Our next task is to try to learn to identify men who should abandon medical therapy (those destined to fail as time progresses) early on and be counselled to undergo operative therapy when they are younger, healthier, and can expect better outcomes.

Competing interests: Dr. Nickel has been a consultant for Alivio, Farr Labs, Inmunotek, Kanglaite, MicroGenDx, Redleaf Medical, Seikagaku Corp, TEVA, Urogen Pharma, and Valensa Int; has participated in scientific studies/trials supported by CIHR, Inmunotek, MicroGenDx, NIH, and Redleaf Medical; and is the Editor of AUA Update Series.

\section{References}

1. Borth CS, Beiko DT, Nickel JC. Impact of medical therapy on transurethral resection of the prostate: A decade of change. Urology 2001;57:1082-5. https://doi.org/10.1016/S0090-4295(01)01018-4

2. Izard J, Nickel JC. Impact of medical therapy on transurethral resection of the prostate: Two decades of change. BJU Int 2011;108:89-93. https://doi.org/10.1111/i.1464-410X.2010.09737.x

3. LaBossiere JR, Wallis CJD, Herschorn S, et al. Surgical management of benign prostatic obstruction: 20-year population-level trends. Can Urol Assoc J 2020;14:252-7. http://dx.doi.org/10.5489/cuai.6224

Correspondence: Dr. J. Curtis Nickel, Department of Urology, Queen's University, Kingston, ON, Canada; icn@queensu.ca 